\title{
A internacionalização da produção das diferentes gerações de pesquisadores CNPq de Geografia Física do Brasil
}

\section{The internationalization of scientific production in different generations of CNPq Physical Geography researchers in Brazil}

\author{
André Augusto Rodrigues Salgado \\ Geógrafo e Mestre em Geografia pela Universidade Federal de Minas Gerais \\ Doutor em Evolução Crustal pela Universidade Federal de Ouro Preto \\ Doutor em Geociências pela Université d'Aix-Marseille na França. \\ Professor Associado IV do Departamento de Geografia da \\ Universidade Federal de Minas Gerais, Brasil. \\ aarsalgadoufmg@gmail.com
}

\section{Resumo}

Os bolsistas de produtividade do $\mathrm{CNPq}$ podem ser considerados a elite em termos de produção científica do Brasil. Deles esperam-se um conjunto constante de publicações de alta qualidade. No entanto, na atualidade a pesquisa de qualidade é cada vez mais entendida como sendo apenas aquela que consegue ser veiculada em periódicos científicos internacionais, de língua inglesa e alto fator de impacto. Em paralelo, faz sentido esperar que a geração mais nova de bolsistas de produtividade do CNPq na área de Geografia Física apresentem produção mais internacionalizada que a mais antiga, pois a demanda por maior internacionalização é ainda recente, bem como os mais novos foram educados em um mundo, inclusive acadêmico, mais globalizado. Neste viés, o presente trabalho analisa a produção publicada em periódicos científicos de todos os bolsistas de produtividade do CNPq na área de Geografia Física no período compreendido entre 2016 e 2020 e compara as diferenças e semelhanças da produção da geração mais antiga com a da mais recente. Os resultados obtidos demonstram não haver grandes diferenças entre a produção das duas gerações sendo, de modo geral, a mais antiga mais produtiva, tanto em artigos nacionais, quanto internacionais. Este fato mostra que a internacionalização da produção científica brasileira na Geografia Física não é um desafio geracional. Em paralelo, os resultados obtidos evidenciaram dois outros fatos: que metade dos bolsistas atuam na subárea de Geomorfologia e Pedologia e que as bolsas de nível 1 se concentram fortemente na geração mais antiga.

Palavras-chave: Artigo científico, Produção do conhecimento, Geomorfologia e Pedologia

\begin{abstract}
CNPq productivity scholarship holders can be considered elite in terms of scientific production in Brazil. Therefore, it is expected from them a constant pool of high-quality publications. However, nowadays, high-quality research is increasingly understood as getting published in scientific, international, English-speaking journals with a high impact factor. In parallel, it makes sense to expect that the younger generation of CNPq productivity scholarship holders in Physical Geography will present a more internationalized production than the older ones, as the demand for greater internationalization is still recent. Furthermore, the younger ones were educated in a world inclusive academic, more globalized. Therefore, this paper analyzes the production published in scientific journals of all CNPq productivity scholarship holders in the field of Physical Geography between 2016 and 2020 and compares the differences and similarities of the production of the older generation with that of the former younger one. The results obtained demonstrate that there are no major differences between the production of the two generations, being, in general, the oldest most productive, both in national and international articles. This fact shows that the internationalization of Brazilian scientific production in Physical Geography is not a generational challenge. In parallel, the
\end{abstract}


results obtained evidenced two other facts: that half of the scholarship holders work in the Geomorphology and Pedology sub-area and that the level 1 scholarships are heavily concentrated in the older generation.

Keywords: Scientific paper, Knowledge production, Geomorphology and Pedology

\section{INTRODUÇÃO}

Nos últimos anos, foi crescente a demanda por um aumento da produtividade e pela internacionalização dos programas de pós-graduação no Brasil. Neste processo, os estratos mais altos do sistema de avaliação da CAPES foram reservados para os programas que, além de produtivos, conseguissem alcançar alto grau de internacionalização. No entanto, produzir conhecimento e internacionalizá-lo não é um processo simples. Principalmente naquele que é o melhor parâmetro para se mensurar a real repercussão internacional de um pesquisador ou de um programa de pósgraduação: as publicações em periódicos internacionais com alto fator de impacto. Esse tipo de publicação atende aos requisitos de produção com qualidade e de internacionalização ao mesmo tempo, e assim demonstra de forma inquestionável que um programa de pós-graduação ou que um pesquisador está internacionalizado e sendo produtivo. Entretanto, ainda há diferença entre as grandes áreas. A da Saúde e a da Exatas e da Natureza valorizam extremamente a produção internacional, pois seus pesquisadores publicam com maior frequência em inglês e seus estratos mais altos do sistema de avaliação dos periódicos - o Qualis CAPES (CAPES, 2021) - são reservados para os periódicos internacionais com alto fator de impacto. Já na grande área das Humanidades, o sistema é outro, pois de modo geral há pouca produção internacional e nos estratos mais altos do Qualis CAPES podem ser encontrados diversos periódicos nacionais, que publicam quase que somente em português e que não possuem sequer fator de impacto. Logo, na grande área das Humanidades, em termos de publicações, é possível ser considerado altamente produtivo, sem necessariamente se internacionalizar. Isso estabelece uma parcial cisão na Ciência brasileira entre as diferentes três grandes áreas do saber no que tange ao entendimento do que são boas publicações e no que se refere a como identificar um pesquisador altamente produtivo.

A Geografia Física se encontra na fronteira entre duas grandes áreas da Ciência: a da Humanidades e da Exatas e da Natureza. Por suas características intrínsecas, é uma Ciência exata e natural, mas em termos de estrutura administrativa do governo brasileiro, está inserida dentro da grande área das Humanidades junto com a Geografia Humana (CAPES, 2019). Este fato por si só já torna a situação da Geografia Física brasileira complexa e acaba por se refletir no próprio perfil de publicações da área. De fato, apesar de estar mais acostumada a publicar em periódicos com fator de 
impacto do que a maior parte das outras subáreas das humanidades, de um modo geral a Geografia Física ainda enfrenta grandes dificuldades com as publicações internacionais (SALGADO, 2017; SALGADO; MARTINS, 2020). Inclusive em razão de que a publicação internacional de alto impacto, por ser equiparada com a nacional no sistema Qualis CAPES Geografia (CAPES, 2021), acaba deixando de ser um objetivo primordial. É fato que um geógrafo físico no Brasil pode ter diversas publicações nos estratos mais altos do sistema, sem jamais ter tido um artigo aceito em um periódico internacional e/ou com fator de impacto. Por consequência, a publicação internacional em periódico com bom fator de impacto está, na Geografia brasileira, resumida a um seleto grupo de pesquisadores (SALGADO, 2017). Isto ocorre, inclusive, nos programas de pós-graduação do Brasil mais bem avaliados no sistema CAPES (SALGADO; MARTINS, 2020), sistema este que, contraditoriamente, reserva os melhores níveis de sua avaliação para programas bem internacionalizados (CAPES, 2019).

Inegavelmente, publicar internacionalmente envolve diversos desafios como, por exemplo, dominar uma língua estrangeira - geralmente o inglês -, trabalhar uma questão que tenha relevância internacional, ter amplo domínio da literatura científica que envolve essa questão, ter dinheiro e acesso para utilizar materiais e métodos inovadores, obter dados relevantes e saber muito bem analisálos (Salgado et al., 2020). Ademais, a publicação internacional em Geografia envolve uma série de outras questões um pouco menos explícitas, mas igualmente importantes. Entre elas está encontrar uma área onde um fenômeno ocorra de forma exemplar para que os resultados obtidos pela pesquisa possam ter relevância internacional (SALGADO; OLIVA, 2022). Há também de se ter uma redação mais objetiva e pragmática do que aquela que é comum nas revistas nacionais, visto que os periódicos internacionais são extremamente exigentes com a praticidade do texto. Igualmente importante é saber escolher o periódico para o qual o manuscrito será submetido, pois existem nuances que vão para além do escopo da revista. Após o primeiro parecer, se forem demandadas correções, o pesquisador deve entender que não é necessário apenas corrigir o texto, mas também dialogar com os revisores através de uma longa carta onde todas as alterações realizadas são comentadas e explicadas. Por fim, é necessário entender que o texto submetido não pode focar demais em questões de relevância para o Brasil - estudos de caso específicos -, mas sim naquelas que despertam maior interesse global. Deste modo, saber publicar internacionalmente com boa repercussão, ao menos para a Geografia Física brasileira, aparenta ser um "know-how" adquirido por apenas alguns poucos pesquisadores (SALGADO, 2017; SALGADO; MARTINS, 2020).

Entretanto, nas últimas décadas, foram notáveis os esforços do sistema de pós-graduação brasileiro para internacionalizar seus programas e sua produção. Desde um pouco antes do início do REUNI em 2007, houve um constante investimento para que docentes e discentes brasileiros fizessem 
parte de sua formação e/ou a complementassem no exterior. Esse esforço se estendeu para a grande área das Humanidades e permitiu que muitos dos seus pesquisadores e pós-graduandos tivessem experiência em centros de ensino e/ou pesquisa onde apenas as publicações em periódicos internacionais com alto fator de impacto eram valorizadas. Em paralelo, a internet interconectou o mundo e favoreceu a globalização. As gerações mais novas, independentemente da sua área de atuação, cresceram em um "ambiente social" muito mais internacionalizado do que o dos seus pais. Este impacto foi extremamente forte na academia, pois, entre outros, fez ser mais fácil e rápido o contato entre os pesquisadores brasileiros e os das mais prestigiadas universidades internacionais. Obviamente, é esperado que estes fatores, mesmo que indiretamente, impactem na produção de conhecimento brasileira. Inclusive na da Geografia Física, visto que a área das Humanidades não ficou a margem desse processo.

Diante do acima exposto, o presente trabalho avalia se a publicação internacional de alto impacto constitui um desafio geracional para a Geografia Física brasileira. Se é uma habilidade mais presente para a geração mais nova de pesquisadores brasileiros ou se, ao contrário, é um "know-how" mais individual, independente da geração dos acadêmicos. Esta avaliação será feita através da verificação se as diferentes gerações dos pesquisadores considerados de ponta pelo CNPq em 2021 bolsa de produtividade em pesquisa - em Geografia Física no Brasil apresentam significativas diferenças de produtividade neste quesito. Isto implica em verificar também as publicações nacionais e ver se para este quesito há modificações no perfil de artigos publicados entre as diferentes gerações. A importância deste estudo está em entender se a Geografia Física brasileira tende a se tornar mais produtiva e internacionalizada com o passar dos anos ou se a internacionalização e o crescimento do número das publicações é fruto de esforços isolados de pesquisadores, pouco importando a qual geração eles pertencem.

\section{PROCEDIMENTOS METODOLÓGICOS}

Para atingir os objetivos propostos o CV Lattes de todos aqueles que eram no início de 2021 bolsistas em produtividade em pesquisa em Geografia Física do CNPq foi analisado. Essa análise objetivou contabilizar entre 01 de janeiro de 2016 até 31 de dezembro de 2020 o total de publicações em periódicos e, entre estes, o total publicado em jornais com fator de impacto igual ou superior à 0,500, sendo estes últimos considerados os internacionais. Vale ressaltar que foram contabilizados todos os artigos presentes no CV Lattes do pesquisador, independente do bolsista ser autor ou coautor deles. Em termos de produção total e de produção com fator de impacto igual ou superior à 0,500 em periódicos internacionais, foi calculada à média e a mediana de publicações para as diferentes 
gerações de pesquisadores. A opção por considerar internacionais apenas as publicações em periódicos não editados no Brasil e com fator de impacto igual ou superior a 0,500 visou eliminar deste grupo trabalhos publicados em periódicos que, embora sejam internacionais, tenham pouca repercussão.

Em paralelo, os bolsistas do CNPq foram classificados de acordo com o tipo de bolsa que recebem: nível 1 ou 2. Foram ainda classificados de acordo com sua subárea dentro da Geografia Física. Estas subáreas foram organizadas de acordo com a filiação definida pelo próprio pesquisador em seu CV Lattes e englobaram as seguintes possibilidades: (1) Análise Ambiental; (2) Climatologia; (3) Geomorfologia e Pedologia; (4) Geotecnologias (engloba, entre outros, Cartografia, Sensoriamento Remoto e Geoprocessamento) e; (5) Outros (incluí Biogeografia e Recursos Hídricos entre outras). O objetivo desta classificação foi verificar se o perfil entre gerações varia de acordo com a subárea a qual pertence o pesquisador. Vale ressaltar que a Pedologia foi colocada junto com a Geomorfologia, pois quase todos os pedólogos se classificaram como pedólogos e geomorfólogos ou como pedo-geomorfólogos. Vale ainda ressaltar que, como há muitos poucos bolsistas do CNPq que se autointitulam biogeógrafos e especialistas em Recursos Hídricos, estes foram agrupados na filiação denominada de Outros.

Dado o número de pesquisadores CNPq em Geografia Física ser relativamente diminuto (setenta no total), foram consideradas apenas duas gerações: uma mais antiga e outra mais moderna. A divisão de gerações foi determinada pela mediana do ano de obtenção do doutorado. Aqueles que doutoraram antes do ano onde está a mediana pertencem a geração mais antiga e os que doutoraram depois estão na mais nova. Como a média de ano de obtenção do doutorado foi ligeiramente inferior à mediana, aqueles que obtiveram o título de doutor no ano da mediana foram incorporados à geração mais jovem.

Foi verificada a data da última atualização do CV Lattes de todos os bolsistas em Abril de 2021. Dos setenta, sessenta e seis haviam atualizado seu CV Lattes em 2021, três o haviam feito em 2020 e apenas um não atualizava seu currículo desde antes de 2020. Como aproximadamente 95\% dos pesquisadores tinham atualizado seu CV Lattes em 2021, os números obtidos foram considerados confiáveis. Por fim, vale ressaltar que por motivos éticos nenhuma informação acerca dos pesquisadores contabilizados foi apresentada. Logo, os dados são analisados apenas em relação à geração, nunca em termos do pesquisador individual. 


\section{RESULTADOS}

O CNPq no início de 2021 possuía 70 bolsistas de produtividade em pesquisa na área de Geografia Física, sendo 18 do nível 1 e 52 do nível 2. O mais antigo entre eles havia doutorado em 1987 e o mais novo em 2013. A média do ano de titulação no doutorado era 2002, e a mediana está no ano de 2003. Logo, a geração antiga foi considerada como sendo aquela que se doutorou até o fim de 2002 e a nova a que se doutorou de 2003 em diante. Isto faz com que a geração antiga tenha 33 bolsistas e a nova 37. Dezesseis entre os dezoito bolsistas nível 1 pertencem a geração mais velha (Figura 1). Logo, apenas dois pesquisadores nível 1 pertencem a geração mais jovem. Isto faz com que $48,5 \%$ dos bolsistas da geração antiga sejam nível 1 contra apenas 5,4\% dos da nova geração.

\section{NÚMERO TOTAL DE BOLSISTAS DE PRODUTIVIDADE DA ÁREA DE GEOGRAFIA FÍSICA X NÍVEL E GERAÇÃO}

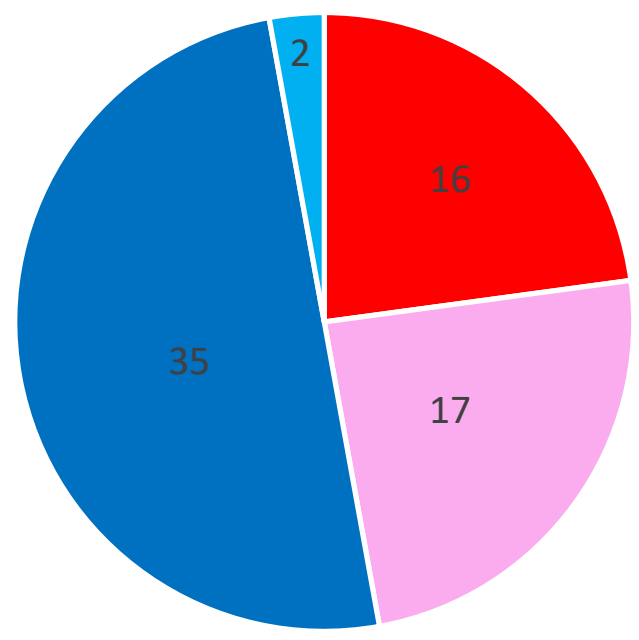

- Geração Antiga Nível 1

- Geração Nova Nível 2
- Geração Antiga Nível 2

- Geração Nova Nível 1

Figura 1: Distribuição dos 70 bolsistas de produtividade em pesquisa do CNPq para a área de Geografia Física no início de 2021 em relação à geração e nível da bolsa.

Entre as subáreas de atuação predomina amplamente a Geomorfologia/Pedologia, tanto no geral, quanto para cada uma das duas gerações (figuras 2, 3 e 4). Neste sentido, apenas uma pequena diferença pode ser notada entre as duas gerações: há um sensível crescimento do número de bolsistas que trabalham com Análise Ambiental entre os mais novos (Figura 4). Entretanto, este crescimento não afetou as duas maiores subáreas: Geomorfologia e Geotecnologias. Ele ocorreu em detrimento do número de bolsistas que trabalham com Climatologia ou com outras subáreas (figuras 2, 3 e 4). 


\section{PERCENTAGEM DE BOLSISTAS POR ÁREA DA GEOGRAFIA FÍSICA}

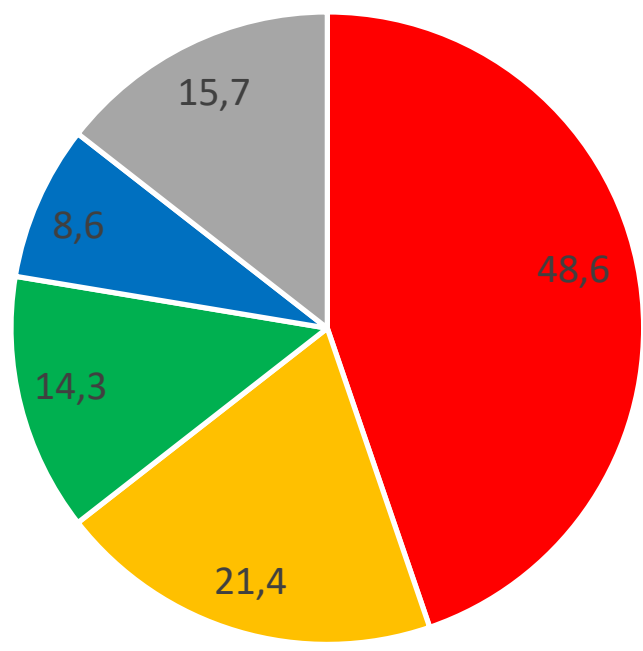

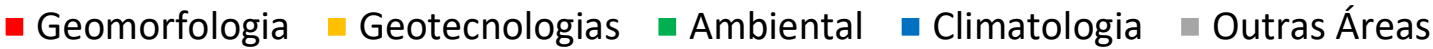

Figura 2: Percentagem da subárea de atuação dos 70 bolsistas de produtividade em pesquisa do CNPq para a área de Geografia Física no início de 2021.

\section{PERCENTAGEM DA SUB-ÁREA DE ATUAÇÃO DOS BOLSISTAS}

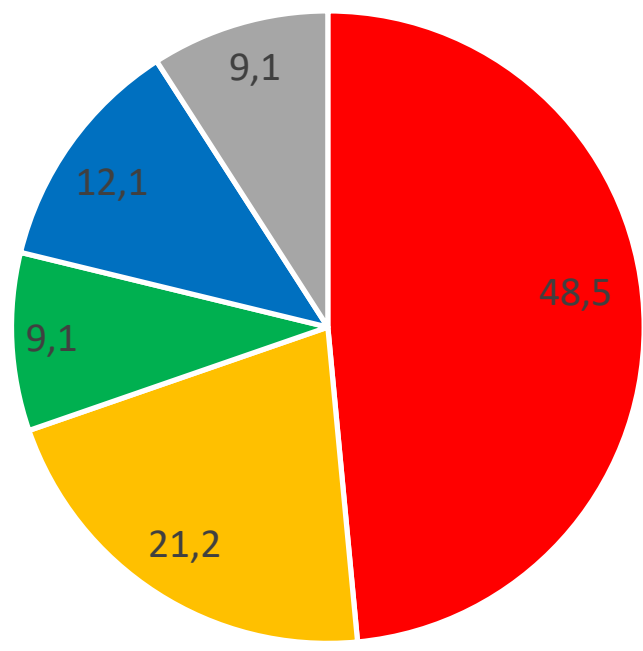

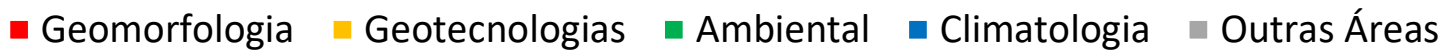

Figura 3: Percentagem da subárea de atuação dos 33 bolsistas de produtividadeem pesquisa do CNPq da geração antiga. 


\section{PERCENTAGEM DE ATUAÇÃO DOS JOVENS BOLSISTAS}

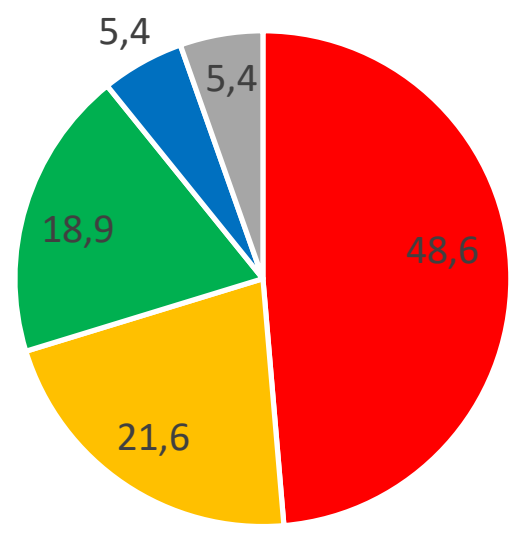

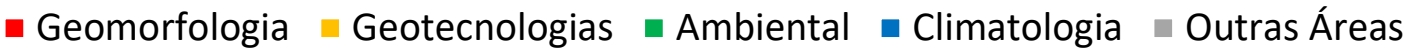

Figura 4: Percentagem da subárea de atuação dos 37 bolsistas de produtividade em pesquisa do CNPq da geração jovem.

A produtividade total de artigos em periódicos para todos os 70 pesquisadores variou entre $6 \mathrm{e}$ 104 artigos publicados no conjunto dos últimos cinco anos (2016-2020). A média foi de 26,5 e a mediana de 24 artigos por pesquisador (Figura 5). A pequena diferença entre a média e a mediana demonstra não existirem notáveis diferenças entre os bolsistas no tocante a produção total de artigos em periódicos. Logo, um bolsista de produtividade em Geografia Física do CNPq publica, em média, aproximadamente cinco artigos por ano. Estes números não são muito diferentes entre as duas gerações. Para a mais antiga, a média é de 28,9 artigos e a mediana está em 25 . Para a mais jovem está em 24,4 na média e 23 na mediana (Figura 5).

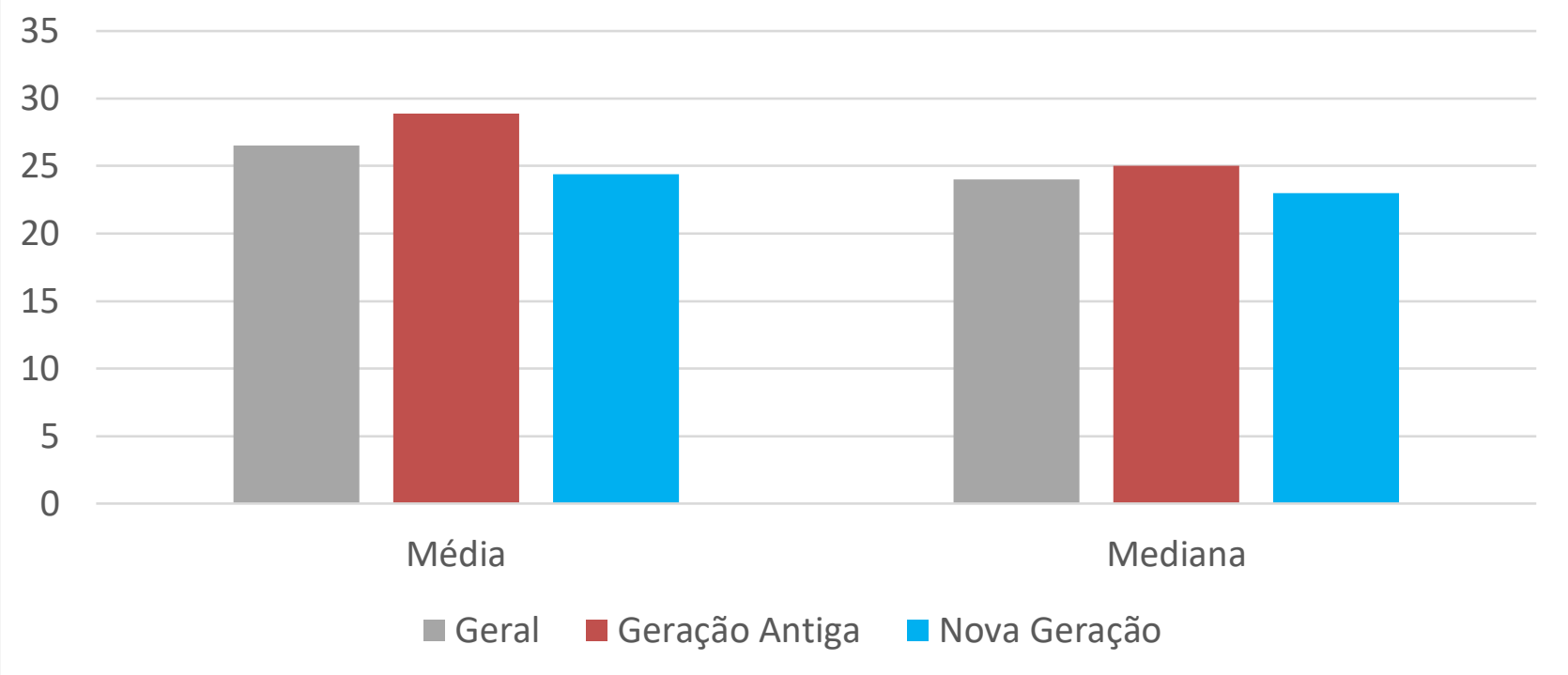

Figura 5: Média e mediana de artigos totais publicados no quinquênio (2016-2020) para o total geral de bolsistas do CNPq, para os da antiga geração e para os da nova geração. 
No que concerne a produção internacional, aquela de maior impacto, para o conjunto de todos os bolsistas do CNPq durante os cinco anos (2016-2020) ela variou entre um mínimo de zero até um máximo de 33 trabalhos. A média foi de 6,0 artigos e a mediana de quatro (Figura 6). Para a geração mais antiga a média foi de 6,7 artigos e a mediana se manteve em quatro. Já para a geração mais jovem a média foi de 5,4 artigos e a mediana também foi quatro. Logo, um bolsista do CNPq que esteja na mediana, não importando o grupo ao qual pertence, publica quase um artigo internacional por ano. Vale ainda ressaltar que como a diferença entre média e mediana é maior para a geração mais antiga, é possível considerar que este tipo de publicação está levemente mais mal distribuído entre os pesquisadores desta geração (Figura 6).

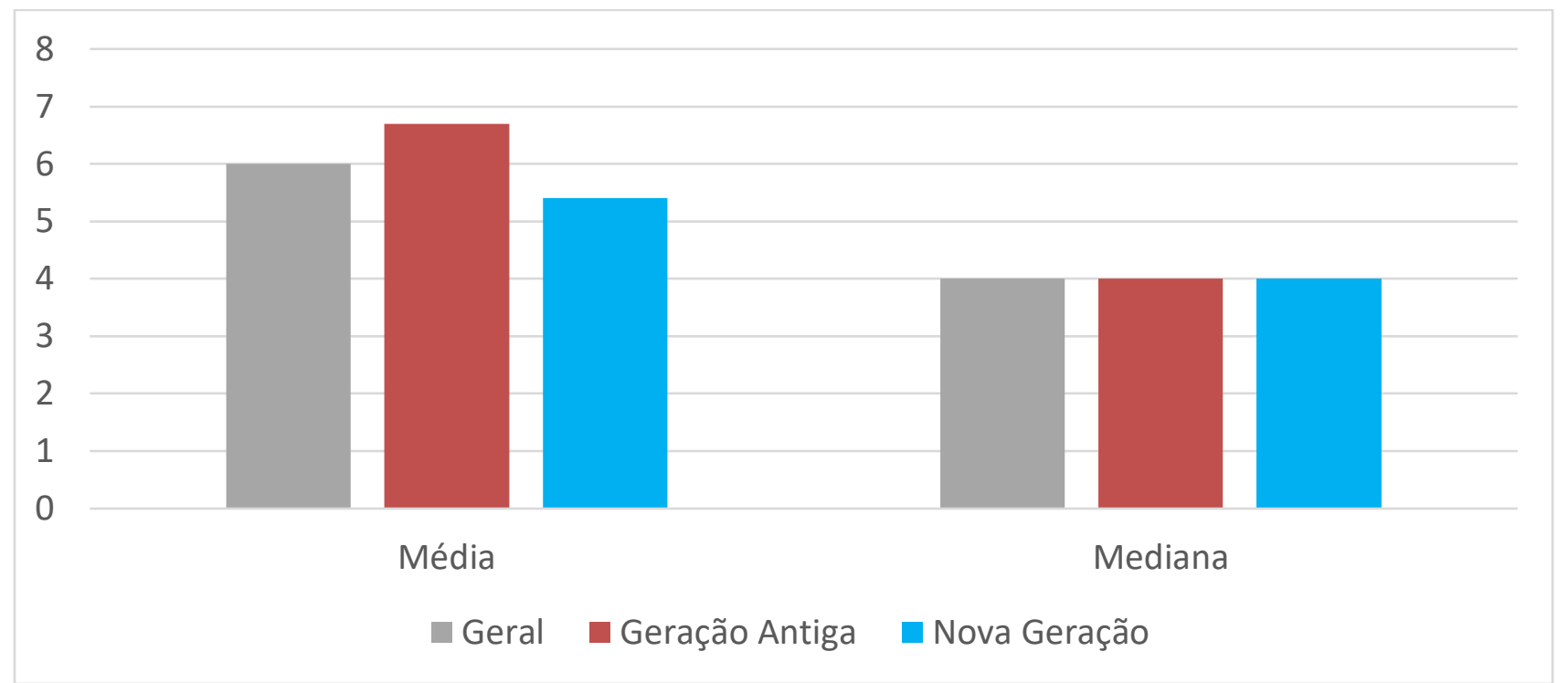

Figura 6: Média e mediana de artigos internacionais publicados no quinquênio (2016-2020) para o total geral de bolsistas do CNPq, para os da antiga geração e para os da nova geração.

Em relação à produção por geração de idade em relação à subárea de atuação, deve-se ressaltar que apenas a subárea Geomorfologia e Pedologia possui mais dez pesquisadores em cada geração. Logo, considerando que as demais subáreas possuem poucos pesquisadores, a comparação fica prejudicada, pois um ou dois bolsistas muito ou pouco produtivos podem elevar ou rebaixar sensivelmente as médias de publicação da subárea do conhecimento. No entanto, a Figura 7 mostra que dependendo da subárea de atuação, a nova geração pode ser mais produtiva do que a antiga na produção total de artigos. Este é o caso das subáreas de Geotecnologias e da Outros. Porém, contra todas as expectativas, nestas duas subáreas a geração mais jovem é, por outro lado, sensivelmente menos produtiva que a mais antiga em termos de publicações internacionais (Figura 8). Esta tendência geral da geração mais antiga ser mais produtiva em termos internacionais se estende para as subáreas Ambiental e Climatologia. Porém, não é verificada na subárea de Geomorfologia e Pedologia, pois neste grupo, e só nele, a nova geração é mais produtiva do que a antiga em termos internacionais 
(Figura 8). Por fim, vale destacar que os bolsistas da geração antiga da subárea Ambiental são, em média e com folga, para os dois tipos de publicação, os mais produtivos.

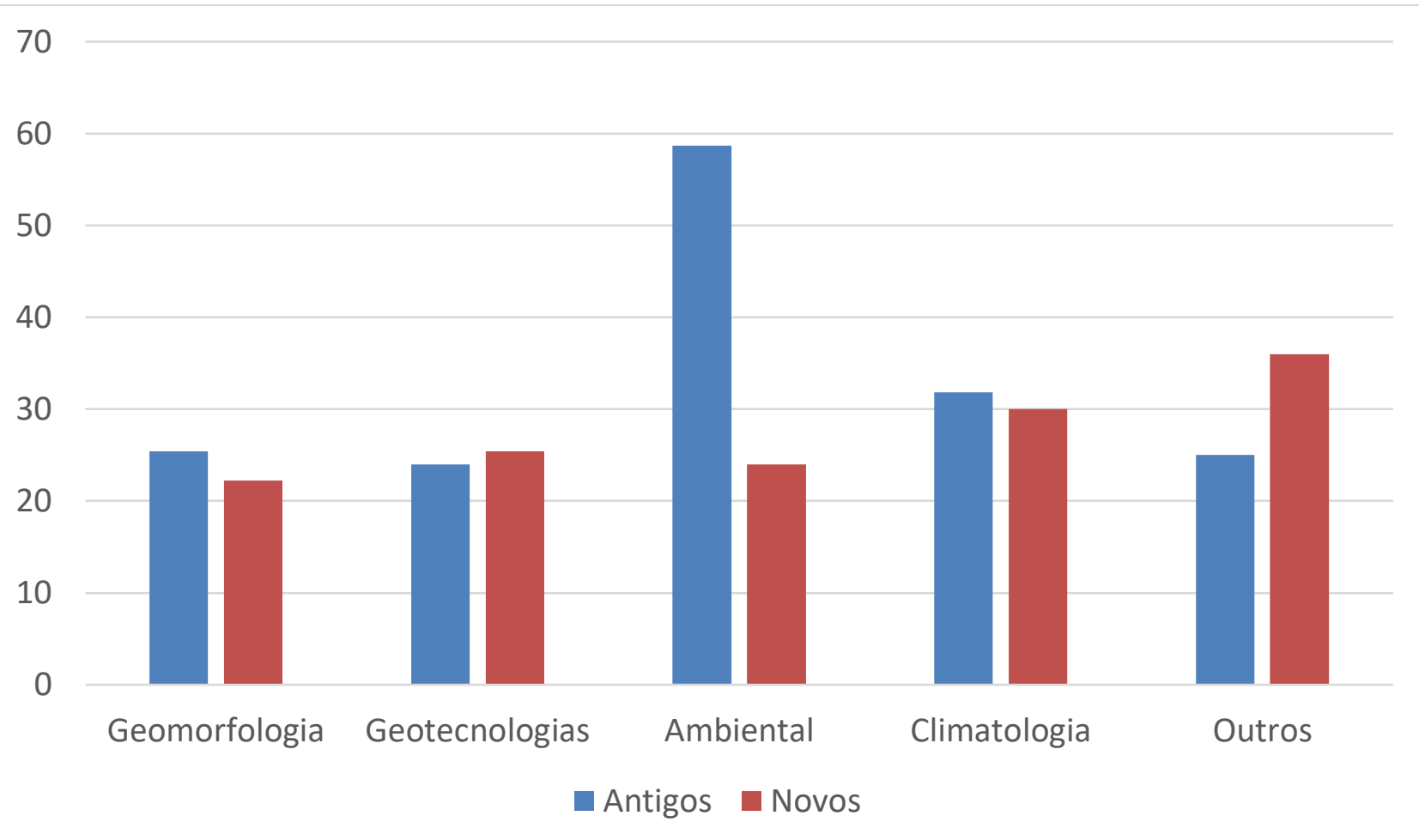

Figura 7: Produção média de artigos nacionais no período analisado (2016-2020) para os bolsistas da nova e da antiga geração por subárea da Geografia Física.

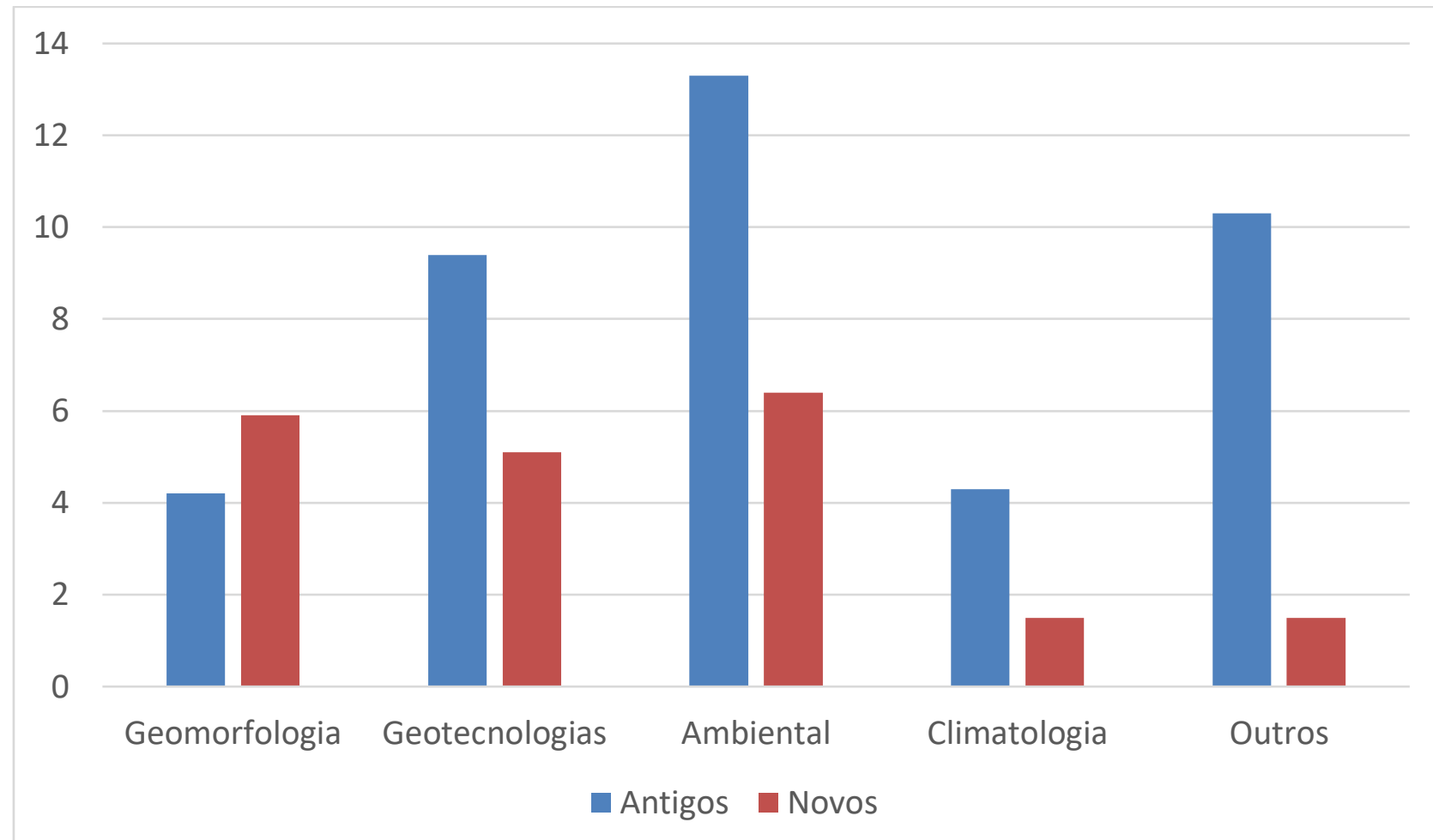

Figura 8: Produção média de artigos internacionais no período analisado (2016-2020) para os bolsistas da nova e da antiga geração por subárea da Geografia Física. 


\section{DISCUSSÕES}

Os resultados encontrados mostram algumas características interessantes na produção bibliográfica em periódicos do grupo de bolsistas CNPq em Geografia Física, ou seja, entre aqueles que devem ser considerados a elite da produção do conhecimento desta vertente da Geografia. $\mathrm{O}$ primeiro fato que merece ser discutido é a quase absoluta concentração das bolsas nível 1 na geração mais antiga de bolsistas, ou seja, na daqueles que doutoraram antes de 2003 (Figura 1). Isso ocorre independentemente de a produção de artigos totais e internacionais ser semelhante entre as duas gerações (figuras 5 e 6). Logo, o fato que define o nível do bolsista não é sua produção bibliográfica total, nacional ou internacional, mas sim outros critérios que estão intimamente relacionados à antiguidade do pesquisador e que podem incluir, entre outros, a experiência acadêmica, a trajetória científica, o renome adquirido, o legado deixado e o número e a qualidade das orientações ao longo da carreira. Sendo assim, se para se tornar bolsista de produtividade em pesquisa do CNPq em Geografia Física um pesquisador precisa ter um bom projeto e publicar muito, para subir de nível os critérios mais importantes são outros. Esta preferência pela maturidade e pela história acadêmica como critérios fundamentais para que um pesquisador CNPq em Geografia Física nível 2 se torne nível 1 é plenamente justificável. No entanto, a concentração das bolsas nível 1 na geração mais antiga é tão intensa que pode chegar a desmotivar os pesquisadores nível 2, pois transmite a sensação que não adianta um esforço extra em termos de produtividade, visto que só o passar dos anos e das aposentadorias lhe permitirá subir o degrau. Por outro lado, pode transmitir para a geração mais antiga a sensação de que também não precisam se esforçar, pois por mais dinâmicos e produtivos que sejam os pesquisadores mais jovens, o critério determinante para a distribuição das bolsas nível 1 será sempre o da antiguidade. É importante observar que as afirmações acima delineadas não necessitam ser de fato o critério que move a escolha dos bolsistas nível 1. Afirma-se apenas que a quase absoluta concentração dos bolsistas nível 1 na geração mais antiga, por mais justa que seja em termos de um sistema que valoriza a maturidade acadêmica, por outro lado pode gerar desmotivação e/ou acomodação entre os bolsistas.

O segundo fato que merece destaque é que quase metade dos setenta bolsistas é composto por geomorfólogos e/ou pedólogos (Figura 2). Esta proporção se mantém estável entre as diferentes gerações de doutores analisadas (figuras 3 e 4) e parece retratar bem a atuação dos acadêmicos brasileiros que trabalham com Geografia Física. Isto é afirmado, pois embora não existam dados acerca do assunto, excluindo-se aqueles profissionais que trabalham com Geografia Humana, os geomorfólogos e pedólogos tendem a dominar os departamentos de Geografia nas universidades públicas brasileiras. 
Ainda no que concerne à subárea de atuação dos bolsistas, são notáveis mais dois fenômenos (figuras 3 e 4): (1) a manutenção entre gerações de um número razoável de profissionais ligados às geotecnologias e; (2) a expansão na nova geração daqueles que trabalham com temas eminentemente ambientais às custas do número de climatólogos, biogeógrafos e outros. Esta também parece ser uma tendência dos quadros profissionais dos departamentos de Geografia no Brasil, pois embora disciplinas de Climatologia e Biogeografia sejam sempre ofertadas, aparentemente é decrescente o número de acadêmicos que em suas atividades de pesquisa trabalham com estes temas. Por outro lado, o número de pesquisadores eminentemente ambientais parece estar crescendo. Já no que se refere às geotecnologias, estas aparentam manter o tamanho e importância nos departamentos de Geografia das universidades públicas brasileiras. Logo, não há muita surpresa nos dados que expressam as especialidades dos bolsistas do $\mathrm{CNPq}$, pois eles aparentam refletir a realidade e as tendências da pesquisa brasileira em Geografia Física.

Conforme dito anteriormente, a comparação entre gerações de pesquisadores por subárea da Geografia Física ficou prejudicada em razão de que à exceção da subárea Geomorfologia e Pedologia, todas as outras quando divididas entre bolsistas da antiga e nova geração, não alcançam dez pesquisadores por sub-grupo. Porém, mesmo assim é possível perceber uma tendência geral para que a geração mais antiga seja um pouco mais produtiva do que a mais nova (figuras 5 e 6 ).

Principalmente em termos de publicações internacionais (figuras 6 e 8) que são aquelas que tendem a ganhar cada vez mais importância. A notável exceção é da subárea de Geomorfologia e Pedologia onde a geração mais nova é mais produtiva do que a mais antiga em termos de publicações internacionais. As razões para este comportamento diferenciado não podem ser explicadas neste trabalho, pois estão muito além dos dados aqui levantados. Entretanto, sejam elas quais forem, não mudam o fato de que há uma ligeira tendência para que os bolsistas em Geografia Física da geração mais antiga (doutores antes de 2003) sejam mais produtivos do que os da mais nova (doutores a partir de 2003) (figuras 5, 6, 7 e 8).

Este fato é muito bem marcado em termos de publicações internacionais, pois desconsiderando a subárea de Geomorfologia e Pedologia, nas subáreas das Geotecnologias, Ambiental e Climatologia a produção internacional da geração mais jovem é aproximadamente apenas metade da mais antiga (Figura 8); e para a subárea Outros alcança somente 20\%. Os números totais de publicações internacionais entre as duas gerações só são semelhantes (Figura 6) em razão de que na subárea Geomorfologia e Pedologia, ou seja, naquela que tem maior peso, pois engloba quase 50\% dos pesquisadores analisados, a geração mais nova apresentar maior produção (Figura 8).

É difícil compreender por qual razão existe um comportamento antagônico entre gerações na produção internacional da subárea Geomorfologia e Pedologia com a das demais subáreas da 
Geografia Física. Na geração mais antiga, os bolsistas que trabalham com Geomorfologia e Pedologia tendem a ser os menos produtivos em termos de artigos internacionais (Figura 8). Na geração mais nova a situação inverte-se, pois os bolsistas CNPq dessa subárea constituem o segundo grupo mais produtivo, só perdendo para os da subárea Ambiental que, nas duas gerações, são aqueles que apresentam a maior produtividade para este tipo de produção. Uma possível explicação para este comportamento diferente do das demais subáreas da Geografia Física pode residir no fato de que a Geomorfologia e a Pedologia tenham sido invadidas nos últimos anos por métodos de análise mais modernos e isso justificaria a maior produtividade da geração mais nova, pois ela já teria sido forjada dentro desse novo paradigma. Entretanto, tal explicação carece de força quando se verifica que a subárea de Geotecnologias também sofreu uma rápida modernização nos últimos anos e nela isso não acarretou um aumento da produtividade da geração mais nova. Logo, a explicação mais plausível talvez esteja no fato de que a maior ou menor produtividade não seja uma questão de geração, mas simplesmente de perfil individual dos pesquisadores.

Neste contexto, abrem-se quatro hipóteses para se explicar a produção bibliográfica segundo geração de bolsistas de produtividade em pesquisa do CNPq de Geografia Física. A primeira é que a geração a qual pertence o pesquisador não tem nenhuma influência em sua produção. A segunda é que os pesquisadores mais antigos, por coordenarem laboratórios mais equipados e equipes mais numerosas e/ou por terem mais experiência, conseguem produzir pesquisas e resultados em maior quantidade e de maior interesse internacional. A terceira seria uma hipotética tendência de a Geografia Física brasileira andar na contramão das tendências globais, com uma geração mais nova potencialmente menos internacionalizada que a mais antiga. Com uma geração mais nova que encontra nos periódicos nacionais com Qualis CAPES Geografia elevados um caminho suficiente para construção de sua reputação como pesquisadores. Por fim, é possível que a explicação esteja em uma quarta possibilidade: uma maior ou menor mistura das três hipóteses anteriores.

\section{CONCLUSÕES}

A divisão dos bolsistas de produtividade em pesquisa do CNPq em Geografia Física do Brasil em dois grupos, um composto por uma geração que se doutorou antes de 2003 e outra por aqueles que o fizeram a partir de 2003, permitiu verificar que ao contrário do que seria esperado, a geração mais velha é mais produtiva em termos de artigos totais e internacionais que a mais nova. A única subárea que apresenta comportamento de expansão das publicações internacionais na geração mais nova é justamente a maior delas: a Geomorfologia e Pedologia. Isto mostra que, para o conjunto das outras subáreas da Geografia Física brasileira, a geração mais nova, mesmo tendo sido criada em um 
ambiente mais globalizado - social e acadêmico - é menos produtiva em termos de artigos internacionais que a mais antiga.

As razões para esta situação não foram aprofundadas no presente trabalho. Entretanto, foram consideradas quatro hipóteses: (i) a primeira é que a produtividade de um pesquisador CNPq não possui relação nenhuma com a sua geração; (ii) a segunda é que a geração mais antiga coordena laboratórios mais estruturados, maiores e que, por possuir pesquisadores mais maduros, com redes de cooperação mais amplas, é capaz de manter uma maior produção de qualidade internacional ; (iii) a terceira é que, apesar de ter crescido em um mundo mais globalizado, a geração mais nova é menos internacionalizada e encontra nos periódicos nacionais um bom meio para construir seus currículos e; (iv) a quarta é uma possível mescla das três hipóteses anteriores.

Por fim, os resultados alcançados explicitaram um fato ainda pouco debatido no grupo de pesquisadores CNPq da área de Geografia Física: uma elevada concentração das bolsas nível 1 na geração mais antiga e a quase completa impossibilidade de um pesquisador da geração mais nova alcançar o nível superior do sistema. Este fato aponta para a consideração que, se para ganhar uma bolsa de produtividade em pesquisa do CNPq é necessário ser muito produtivo em termos de publicações, para subir de nível são mais importantes outros fatores. Estes outros fatores aparentam estar relacionados com a maturidade acadêmica do pesquisador e com a manutenção de uma longa história de orientações, produções, experiências e reconhecimentos.

\section{AGRADECIMENTOS}

Agradecemos ao CNPq pelo apoio financeiro na forma da bolsa (Projeto 102176/2018-3).

\section{REFERÊNCIAS}

CAPES. Documento de Área Geografia. 2019. 33pp. Disponível em: https://www.gov.br/capes/ptbr/centrais-de-conteudo/geografia-pdf. Acesso em: 14 de Abril de 2021.

CAPES. Plataforma Sucupira. 2021. Disponível em: https://sucupira.capes.gov.br/sucupira/. Acesso em: 02 de Maio de 2021.

SALGADO, A. A. R. Produção científica dos professores de cursos de Geografia das universidades federais de Minas Gerais analisada sob a ótica da Teoria das Elites (Princípio de Pareto). Geografias, v. 25, n. 2, 124-134, 2017.

SALGADO, A. A. R.; MARTINS, F. P. A elite da elite: a aplicação do Princípio de Pareto na análise da produção brasileira de conhecimento geográfico de impacto internacional. Caderno de Geografia, v. 30, n. 63, 1183-1194, 2020. 
SAlGADO, A. A. R.; OLIVA, A. Considerações epistemológicas em torno da pesquisa em Geomorfologia: do projeto ao artigo científico. In: CARVALHO JÚNIOR, O. A.; GOMES, M. C. V.; GUIMARÃES, R. F.; GOMES, R. A, T. Revisões de Literatura da Geomorfologia Brasileira. Brasília: União da Geomorfologia Brasileira, 2022, 1.030p.

Trabalho enviado em 16/08/2021 Trabalho aceito em 19/11/2021 